\title{
PENGARUH AKTIVASI REGULASI EMOSI TERHADAP PRESTASI OLAHRAGA ATLET DISABILITAS NPC KOTA SURAKARTA
}

\author{
Kliwon*1, Ari Sarwanto $^{2}$ \\ Poltekkes Kemenkes Surakarta Jurusan Terapi Wicara
}

\begin{abstract}
Background: Many studies have shown how important psychological roles are when enhancing an athlete's ability to deal with match situations. Psychological changes when comparing namely the increase in the ability of athletes to accept stress (pressure), keep concentrating, have a mental toughness (mental toughness) so as to overcome heavier opposition (Hastria Effendi, 2016: 23). Disability sports problems are closely related to psychological problems and symptoms of their athletes. Maximum achievement can be achieved by an athlete who is truly ready to compete with all his abilities. The readiness in question is the physical and psychological aspects of the athlete concerned.The research purpose was determined the effect of emotional regulation activation on the disability athletes' performance in NPC of Surakarta City. Methods: The research type is quantitative research with analytic observational design through a cross-sectional approach. This research was conducted at NPC of Surakarta City. The research population was the Athletes of NPC of Surakarta City. The number of NPC athletes in the Surakarta city which became the researech population amounted to 160 athletes. The sampling technique was used random sampling. Collecting data techniques were used questionnaire, observation, and documentation. Results: The hypothesis testing was used Product Moment Correlation techniques. Conclusion: The research result was showed that there was a close influence between the emotions regulation on the performance of the NPC Surakarta athletes ( $t_{\text {count }}>t_{\text {table }}($ (8.685) $1.571)$ )
\end{abstract}

Keywords: Emotion Regulation, Sports Achievements, NPC Athletes

\section{PENDAHULUAN}

Olahraga merupakan kegiatan yang menjadi sangat populer dan kegiatan yang wajib dilaksanakan dimasyarakat saat ini. Mulai dari anak-anak, remaja sampai yang tua menyukai olahraga. Masyarakat Indonesia akhir-akhir ini mulai menyadari betapa pentingnya olahraga bagi kesehatan diri mereka, samapai terkadang ada sebagian orang yang mengeluarkan banyak uang hanya untuk bisa menikmati olahraga tertentu. Olahraga didefinisikan sebagai segala kegiatan yang sistematis yang dilakukan untuk mendorong, membina serta mengembangkan potensi jasmani, rohani dan sosial (UU No. 3 tahun 2005 tentang Sistem Keolahragaan Nasional).

Secara khusus bagi penyandang cacat atau difabel juga tidak ingin ketinggalan bahwa penyandang difabel juga memiliki bakat dan minat dalam berolahraga. Olahraga difabel menjadi sebuah terobosan baru bagi dunia olahraga yang menunjukkan bahwa olahraga dapat dilakukan oleh atlet normal maupun atlet difabel. Untuk mewadahi atlet difabel agar bisa 
berprestasi secara optimal mereka dibina melalui wadah NPC (National Paralympic Committee) yang ada di tiap kota/kabupaten di Indonesia.

NPC Kota Surakarta senantiasa selalu berjuang untuk membina atlet penyandang disabilitas di Kota Surakarta hingga kini telah banyak memiliki prestasi yang diraih dalam berbagai kompetisi baik di tingkat nasional maupun internasional. Atlet binaan NPC Kota Surakarta diseleksi dengan beberapa tahap, antara lain tahap seleksi fisik, klasifikasi ketunaan dan pemilihan cabang olahraga yang tepat bagi klasifikasi ketunaannya. Saat ini ini NPC Kota Surakarta membina 12 cabang olahraga dengan jumlah atlet sebanyak 160 orang.

Banyak studi yang menunjukkan betapa pentingnya peranan psikologis ketika meningkatkan kemampuan seorang atlet dalam menghadapi situasi pertandingan. Perubahan psikologis saat petandingan yakni meningkatnya kemampuan atlet dalam menerima stress (tekanan), tetap berkonsentrasi, memiliki ketegaran mental (mental toughness) sehingga mampu mengatasi tentangan yang lebih berat (Hastria Effendi, 2016: 23).

Permasalahan olahraga difabel sangat berhubungan dengan masalahmasalah dan gejala-gejala psikologis atetatletnya. Prestasi maksimal dapat dicapai oleh seorang atlet yang benar-benar telah siap untuk berkompetisi dengan segala kemampuannya. Kesiapan yang dimaksud adalah fisik dan fsikologis atlet yang bersangkutan.

Prestasi olahraga itu tidak hanya bergantung kepada keterampilan teknis olahraga dan kesehatan fisik yang dimiliki atlet yang bersangkutan, tetapi juga bergantung pada keadaan psikologis dan kesehatan mentalnya. Salah satu pembinaan psikologis yang perlu dikembangkan untuk seorang atlet adalah regulasi emosi (Alfarabi, Amiruddin, Masri. 2017: 249).

Regulasi emosi (emotion regulation) adalah suatu proses, luar dan dalam, kesadaran dan ketidaksadaran akan pengaruh dari bagian emosi yang mengabungkan, mewujudkannya, berdasarkan situasi dari fakta-fakta, dan berjalannya konsekuensi yang akan terjadi (Gross dalam Alfarabi, Amiruddin, Masri. 2017: 249). Selanjutnya Gross membagi regulasi emosi menjadi dua komponen, yaitu reappraisal dan suppression. Reappraisal (penilaian kembali), yaitu perubahan kognitif dalam menetralkan dampak negatif emosi atau menjelaskan aspek peristiwa keluarnya emosi yang positif. Suprression (tekanan), yaitu bentuk dari respon modulasi yang menghambat tingkah laku terus-menerus dengan penindasan emosi.

Regulasi emosi berhubungan dengan suasana hati. Konsep regulasi emosi itu luas dan meliputi kesadaran dan ketidaksadaran secara psikologis, tingkah laku, dan proses kognitif. Selain itu, regulasi emosi beradaptasi dalam kondisi situasi emosi yang stimulusnya berhubungan dengan lingkungan. Individu yang mampu melakukan regulasi emosi dengan baik ia akan menunjukan ekspresi emosi yang lebih positif sebaliknya jika individu kurang mampu melakukan regulasi emosi maka ia cenderung menunjukan ekspresi emosi negatif.

Pengelolaan regulasi yang baik akan menghasilkan prestasi olahraga yang tinggi. Atlet yang mampu mengatasi berbagai setiap gangguan, tuntutan, kecemasan dan berbagai macam kesulitannya tentu akan memiliki prestasi 
yang lebih baik dari mereka yang tidak mampu mengatasinya. Terdapat salah satu konsep yang dapat menggambarkan hal tersebut, yaitu resiliensi. Resiliensi mengacu pada kemampuan seseorang untuk mampu beradaptasi secara positif dengan segala macam kesulitan yang dihadapinya (Khoirunnisa, 2014: 3).

\section{METODE PENELITIAN}

Desain penelitian merupakan semua proses yang diperlukan dalam perencanaan dan pelaksanaan penelitian (Nazir, 2003). Jenis penelitian ini adalah penelitian kuantitatif dengan rancangan analitic observational melalui pendekatan potong lintang (Cross Sectional). Penelitian ini dilaksanakan di NPC Surakarta dilaksanakan selama 12 bulan mulai bulan Januari 2019 sampai dengan Desember 2019. Metode yang digunakan dalam penelitian ini adalah metode korelasional yang bertujuan untuk menemukan ada tidaknya hubungan dan apabila ada, seberapa erat hubungan serta berarti atau tidaknya hubungan tersebut (Arikunto. 2002:239).

Populasi dalam penelitian ini adalah Atlet NPC Kota Surakarta. Jumlah atlet NPC Kota Surakarta yang menjadi populasi pada penelitian ini berjumlah 160 atlet. Teknik sampling yang digunakan dalam penelitian ini adalah random sampling. Teknik ini mengambil sampel secara acak hal tersebut sesuai dengan pendapat Thoifah (2015:21) teknik random sampling adalah teknik simpel (sederhana) karena pengambilan sampel secara acak dari anggota populasi tanpa memperdulikan strata yang ada sehingga setiap anggota populasi memiliki peluang yang sama untuk dipilih sebagai anggota sampel. Sampel dalam penelitian ini berjumlah 60 atlet. Untuk mendapatkan data yang diperlukan dalam penelitian ini digunakan bermacam teknik pengumpula data. Teklnik pengumpulan data yang digunakan dalam penelitian ini diantaranya: kuesioner, observasi, dan dokumentasi.

Untuk validitas butir dilakukan dengan analisis korelasi Product Moment antara skor tiap butir dengan skor total. Sedangkan reliabilitas instrumen dihitung dengan menggunakan Aplha Cronbach untuk mengetahui konsistensi internal instrumen tersebut. Reliabilitas instrumen dimaksud untuk melihat konsistensi jawaban yang diberikan pada responden dan dianalisis dengan menggunakan Alpha Cronbach.

Sebelum pengujian hipotesis dilakukan terlebih dahulu dilakukan uji normalitas yang bertujuan untuk mengetahui apakah data yang diperoleh berasal dari populasi didistribusi normal atau tidak. Uji normalitas yang dipakai menggunakan teknik one sample kolmogrovsmirnov. Uji Linieritas dilakukan untuk menguji apakah pola sebaran variabel $\mathrm{X}$ dan variabel $\mathrm{Y}$ membentuk garis linier atau tidak. Perhitungan korelasi parsial menggunakan bantuan SPSS.16 untuk melihat hubungan yang paling kuat dari indikator regulasi emosi dengan prestasi oleharaga. Analisis dalam penelitian ini, data yang akan dikorelasikan berbentuk interval, maka dari itu untuk menguji hipotesis hubungan, akan diuji dengan menggunakan teknik korelasi Product Moment.

\section{HASIL PENELITIAN Uji Prasyarat Analisis Uji Validitas}

Uji validitas dilaksanakan untuk menentukan tingkat kevalidan pertanyaan 
kuessioner. Validitas diuji dengan product moment (pearsson correlation), dimana jika $\mathrm{r}_{\text {hitung }}$ (koefisien korelasi) lebbih besar dari $r_{\text {tabel }}$ (nilai kritis) pada taraf signifikan 5\% atau 0,05 maka pertanyaan kuesioner tersebut memenuhi kriteria validitas. Bila $\mathrm{r}$ hitung (koefisien korelasi) bernilai lebih kecil dari $r$ tabel (nilai kritis) maka pertanyaan kuesioner tidak memenuhi kriteria validitas.

Berdasarkan hasil pengujian validitas data bahwa variabel regulasi emosi dan variabel prestasi menunjukkan bahwa seluruh data yang diperoleh adalah valid $(<0,05)$, dengan demikian semua pertanyaan kuesioner dapat digunakan dan dapat dipercaya untuk mengumpulkan data dan data dapat diolah lebih lanjut untuk menentukan analisis selanjutnya.

\section{Pengujian Reliabilitas}

Uji reliabilitas dilaksanakan untuk menguji kemanttapan dan kekonsistenan kuesioner yang digunakan. Kuesioner dengan nilai reliabilitas yang baik akan diperoleh hasil yang sama meskipun digunakan berulang kali oleh orang yang berlainan. Kuesioner dikatakan reliabel jika nilai Cronbach Alpha lebih dari 0,7. Hasil analisis menunjukkan bahwa semua instrumen variabel penelitian memiliki nilai Cronbach Alpha lebih dari 0,7 sehingga dapat dinyatakan seluruh variabel reliabel atau dapat dihandalkan.

\section{Analisis Data Penelitian Normalitas}

Uji Normalitas dimaksudkan untuk mengetahui penyebaran residu dari hasil analisis regresi. Uji normalitas residu dilakukan dengan menggunakan uji non parametrik, yaitu Kolmogorov Smirnov test (K-S test). Dari hasil analisis diketahui hasil $\mathrm{Z}$ sebesar 0,623 dan nilai signifikansi sebesar 0,832. Karena nilai signifikansi lebih besar dari 0,05 maka $\mathrm{Z}$ tidak signifikan yang berarti Ho diterima. Karena Ho diterima maka disimpulkan bahwa data residu hasil estimasi dari persamaan regresi memiliki penyebaran yang normal. Dengan demikian maka model regresi dalam penelitian ini telah memenuhi syarat asumsi klasik.

Tabel 1. Uji Normalitas

\begin{tabular}{|c|c|c|}
\hline & & $\begin{array}{c}\text { Unstandardized } \\
\text { Residual } \\
\end{array}$ \\
\hline \multicolumn{2}{|l|}{$\mathrm{N}$} & 54 \\
\hline \multirow{3}{*}{$\begin{array}{l}\text { Normal } \\
\text { Parameters }\end{array}$} & Mean & $0 \mathrm{E}-7$ \\
\hline & Std.Deviation & ,08400105 \\
\hline & Absolute & ,085 \\
\hline Most Extreme & Positive & ,063 \\
\hline \multirow{3}{*}{\multicolumn{2}{|c|}{$\begin{array}{l}\text { Differences } \\
\text { Kolmogorov-Smirnov Z } \\
\text { Asymp.Sig.(2-tailed) }\end{array}$}} &,- 085 \\
\hline & & 623 \\
\hline & &, 832 \\
\hline
\end{tabular}

Sumber : Data primer diolah 2019

\section{Linieritas}

Uji ini dilakukan untuk mengetahui apakah variabel bebas (X) dan variabel terikat (Y) mempunyai hubungan yang linier. Untuk mengujinya dilakukan dengan uji $\mathrm{F}$ penyimpangan data dari garis linier (deviation from linierity) yang digunakan untuk memprediksikan model. Kriteria yang digunakan untuk menguji Linearitas adalah jika nilai $p$ pada uji regresi menunjukkan hasil yang tidak signifikan $(<0,05)$, maka disimpulkan korelasi yang diuji mempunyai model linier, sebaliknya jika hasil signifikansi hasilnya signifikan maka dapat disimpulkan terjadi hubungan yang tidak linier. Atau dapat menggunakan cara lain yaitu dengan membandingkan nilai Fhitung dengan $\mathrm{F}$ tabel, yaitu apabila nilai $\mathrm{F}_{\text {hitung }}<\mathrm{F}_{\text {tabel }}$ maka terjadi korelasi yang linier. 
Tabel 2. Hasil Uji Linearitas

\begin{tabular}{lllll}
\hline Variabel & $\mathbf{F}_{\text {hitung }}$ & $\mathbf{F}_{\text {tabel }}$ & p-value & Ket \\
\hline $\begin{array}{l}\text { Regulasi } \\
\text { emosi }\end{array}$ & & & & \\
$\begin{array}{l}\text { terhadap } \\
\text { prestasi } \\
\text { olahraga }\end{array}$ & 1,124 & 3,92 & 0,311 & Linier \\
\hline
\end{tabular}

Sumber: Data primer diolah 2019

Berdasarkan tabel di atas, terlihat bahwa nilai $\mathrm{F}_{\text {hitung }}<\mathrm{F}_{\text {tabel }}(1,124>3,92)$, maka dapat disimpulkan bahwa korelasi antara regulasi emosi dengan prestasi olahraga adalah linier.

\section{a. Uji Hipotesis}

\section{Uji Regresi Linier Sederhana}

Metode regresi linier sederhana ini dimaksudkan untuk mengetahui seberapa besar tingkat pengaruh antara reegulasi emosi dengan prestasi olahraga. Untuk itu peneliti sajikan hasil uji regresi linier sederhana berdasarkan tabel berikut:

Tabel 3. Hasil Persamaan Regresi Linier Sederhana

\begin{tabular}{lccc}
\hline \multirow{2}{*}{ Model } & \multicolumn{2}{c}{$\begin{array}{c}\text { Unstandardzed } \\
\text { Coefficients }\end{array}$} & $\begin{array}{c}\text { Standardzed } \\
\text { Coefficients }\end{array}$ \\
\cline { 2 - 4 } & B & Std.Error & Beta \\
\hline (Contant) & .631 & .181 & \\
re & .735 & .085 & .667 \\
\hline
\end{tabular}

Sumber: Data primer diolah 2019

Pada output ini, dikemukakan nilai koefisien dari persamaan regresi. Dalam kasus ini, persamaan regresi sederhana yang digunakan adalah:

Dimana :

$$
\mathbf{Y}=\mathbf{a}+\mathbf{b X}
$$

$\mathrm{Y}=$ Prestasi Olahraga

$\mathrm{X}=$ Regulasi Emosi

Dari output didapatkan model persamaan regresi:

$$
\mathrm{Y}=\mathbf{0 , 6 3 1}+\mathbf{0 , 7 3 5} \mathrm{X}
$$

Koefisien-koefisien

persamaan regresi linier sederhana di atas dapat diartikan koefisien regresi untuk konstan sebesar 0,631 menunjukan bahwa jika variabel regulasi emosi bernilai nol atau tetap maka akan meningkatkan prestasi olahraga sebesar 0,631 satuan atau sebesar $63,1 \%$. Variabel regulasi emosi 0,735 menunjukkan bahwa jika variabel regulasi emosi meningkat 1 satuan maka akan meningkatkan prestasi olahraga sebesar 0,735 satuan atau sebesar $73,5 \%$.

\section{Uji Determinasi (R Square)}

Koefisien determinasi ( $\mathrm{R}$ square) bertujuan untuk mengetahui seberapa besar kemampuan variabel independen regulasi emosi mampu menjelaskan variabel dependen (prestasi olahraga). Berikut ini hasil uji determinasi $(R$ Square).

Tabel 4. Hasil Uji Determinasi

\begin{tabular}{cccccc}
\hline Model & $\mathbf{R}$ & $\begin{array}{c}\mathbf{R} \\
\text { Square }\end{array}$ & $\begin{array}{l}\text { Adjusted } \\
\text { R Square }\end{array}$ & $\begin{array}{l}\text { Std.Error } \\
\text { Of the } \\
\text { Estimate }\end{array}$ & $\begin{array}{l}\text { Durbin- } \\
\text { Watson }\end{array}$ \\
\hline 1 & .667 & .445 & .439 & .29435 & 1.975 \\
\hline
\end{tabular}

a.Predictors : (Contant),re

b.Dependet variable:pres

Sumber: Data primer diolah 2019

Berdasarkan kepada tabel di atas diketahui nilai $R$ square sebesar 0,445 $(44,5 \%)$, Ini menunjukkan bahwa dengan menggunakan model regresi yang didapatkan dimana variabel independen yaitu regilasi emosi memiliki pengaruh terhadap variabel prestasi olahraga sebesar $44,5 \%$. Sedangkan sisanya $55,5 \%$ dijelaskan dengan faktor atau variabel lain yang tidak diketahui dan tidak termasuk dalam analisis regresi ini.

\section{Uji Hipotesis (Uji t)}

Pengujian hipotesis secara parsial dimaksudkan untuk mengetahui ada atau tidaknya pengaruh variabel bebas secara parsial terhadap variabel terikat. Hasil hipotesis dalam pengujian ini adalah: 
Tabel 5. Hasil Uji Hipotesis (Uji t)

\begin{tabular}{lcl}
\multicolumn{1}{c}{ Model } & $\mathbf{t}$ & Sig \\
\hline (Contant) & 3.483 & .001 \\
re & 8.685 & .000 \\
\hline
\end{tabular}

a. Dependent Variabel:pres

Sumber: Data primer diolah 2019

Pada tabel di atas, $t_{\text {hitung }}$ pada regulasi emosi adalah 8,685. Pada derajat bebas $(\mathrm{df})=\mathrm{N}-1=60-1=59$, maka ditemukan $t_{\text {tabel }}$ sebesar 1,671. Maka dapat ditarik kesimpulan bahwa $t_{\text {hitung }}>t_{\text {tabel }}$ $(8,685>1,671)$.

Dari hasil analisis data penelitian di atas, maka dapat ditarik kesimpulan bahwa regulasi emosi berpengaruh signifikan terhadap prestasi olahraga atlet NPC Kota Surakarta. Sehingga hipotesis yang menyatakan terdapat pengaruh regulasi emosi terhadap prestasi olahraga atlet NPC Kota Surakarta terbukti kebenarannya atau dapat diterima.

\section{PEMBAHASAN}

Hasil perhitungan korelasi product moment dengan menggunakan bantuan SPSS 16 menunjukkanbahwa $t_{\text {hitung }}$ pada regulasi emosi adalah 8,685. Pada derajat bebas $(\mathrm{df})=\mathrm{N}-1=60-1=59$, maka ditemukan $t_{\text {tabel }}$ sebesar 1,671, sehingga $t_{\text {hitung }}>t_{\text {tabel }}(8,685>1,671)$, maka Ho ditolak dan Ha diterima. Berarti regulasi emosi berpengaruh signifikan terhadap prestasi olahraga.

Regulasi emosi atlet NPC Kota Surakarta masuk dalam kategori baik. Menurut hasil penelitian Gross (dalam Cisler,2010) mengatakan individu yang memiliki regulasi emosi yang baik akan melakukan penilaian kembali pada emosi dan dapat mengendalikan instruksi pada penekanan kecemasan, sebaliknya individu yang memiliki regulasi emosi yang buruk tidak dapat melakukan penilaian kembali pada emosi agar dapat mengendalikan diri.

Menurut penelitian Deci Nansi dan Fajar Tri Utami, 2016: 27), regulasi emosi sebagai pemikiran atau perilaku yang dipengaruhi oleh emosi. Ketika mengalami emosi yang negatif, orang biasanya tidak dapat berfikir dengan jernih dan melakukan tindakan di luar kesadaran. Regulasi emosi adalah bagaimana seseorang dapat menyadari dan mengatur pemikiran dan perilakunya dalam emosi-emosi yang berbeda (emosi positif dan negatif).

Atlet yang memiliki regulasi emosi yang baik akan memiliki motivasi berpretasi yang lebih tinggi. Menurut Mc Clelland dalam (Rubianto Hadi, 2007: 7275) individu yang memiliki motivasi berprestasi tinggi memiliki tanggung jawab yang penuh dalam menjalankan program latihan yang diberikan kepadanya dengan bersungguh-sungguh dan disiplin tinggi. Tanggung jawab dan disiplin yang tinggi dapat dilihat dari tepat waktunya dalam latihan, tidur, menjaga asupan makanan, serta melakukan latihan dengan semangat dan bersungguh-sungguh.

Atlet dengan motivasi berprestasi tinggi cenderung memilih aktivitas yang menantang namun tidak berada di atas taraf kemampuan dan cenderung memilih aktivitas dengan derajat sedang yang memungkinkan berhasil. Mereka menghindari tugas yang dirasa terlalu mudah karena sedikitnya tantangan atau kepuasan yang didapat. Misalnya, seseorang yang belum bisa melakukan jumping smash akan berusaha keras agar berhasil walaupun dengan resiko bisa cidera.

Atlet yang melakukan evaluasi baik saat berhasil maupun gagal dan meminta 
umpan balik kepada pelatih adalah atlet yang mempunyai motivasi berprestasi yang tinggi. Ia lebih suka berlatih dalam situasi dimana ia dapat memperoleh umpan balik yang konkret tentang apa yang sudah ia lakukan. Karena jika tidak, mereka tidak dapat mengetahui apakah mereka sudah melakukan sesuatu dengan baik dibandingkan yang lain atau belum. Umpan balik ini selanjutnya akan dipergunakan untuk memperbaiki prestasinya. Atlet dengan motivasi berprestasi tinggi biasanya sering melakukan inovasi dalam bermain dengan melakukan cara atau sesuatu yang beda dari sebelumnya. Ia akan lebih sering mencari informasi untuk menemukan cara yang lebih baik dalam melakukan suatu dan lebih inovatif sehingga dapat menemukan taktik dan strategi yang baik dalam mengatasi lawan-lawannya.

\section{KESIMPULAN DAN SARAN}

Kesimpulan:

Berdasarkan hasil analisis data dapat disimpulkan bahwa berarti terdapat pengaruh yang erat antara regulasi emosi terhadap prestasi olahraga atlet NPC Kota Surakarta. Hal ini dibuktikan dari hasil uji $\mathrm{t}$ ditemukan bahwa $\mathrm{t}_{\text {hitung }}>\mathrm{t}_{\text {tabel }}((8,685>$ 1,571) maka Ho ditolak secara statistik adalah signifikan.

Saran:

Dari hasil pembahasan peneliti ingin mengajukan beberapa saran. Pelatih hendaknya lebih mencermati aspek psikologis atlet khususnya dalam hal regulasi emosi karena keberhasilan atlet untuk mencapai prestasi olahraga.

\section{DAFTAR RUJUKAN}

Alfarabi, Amiruddin, Masri. 2017. Persepsi Masyarakat Banda Aceh Terhadap Prestasi Olahraga
Taekwondo. Jurnal Ilmiah Mahasiswa Pendidikan Jasmani, Kesehatan dan Rekreasi Fakultas Keguruan dan Ilmu Pendidikan Unsyiah Volume 3, Nomor 4: 248-258 November 2017

Arif Hidayat, Nanang Indardi. 2015. Survei Perkembangan Olahraga Rekreasi Gateball di Kabupaten Semarang. Journal of Sport Sciences and Fitness. JSSF 4 (4) (2015).

Arikunto, S. 2002. Prosedur Penelitian Suatu Pendekatan Praktik. Jakarta PT. Rineka Cipta

Deci Nansi dan Fajar Tri Utami. 2016. Hubungan Antara Regulasi Emosi Dengan Perilaku Disiplin Santri Madrasah Aliyah Pondok Pesantren Qodratullah Langkan. PSIKIS-Jurnal Psikologi Islami Vol. 2 No. 1 (2016) 16-28

Gross, James J. 2007. Handbook of Emotion Regulation. New York : The Guilford Press.

Hastria Effendi. 2016. Peranan Psikologi Olahraga Dalam Meningkatkan Prestasi Atlet. Nusantara ( Jurnal Ilmu Pengetahuan Sosial) Volume 22, 1 Desember 2016. ISSN 2541$657 \mathrm{X}$

Rubianto Hadi. 2007. Ilmu Kepelatihan Dasar. Semarang: CV. Cipta Prima Nusantara

Thoifah. 2015 . Statistika Pendidikan dan Metode Penelitian Kuantitatif. Malang : Madani 